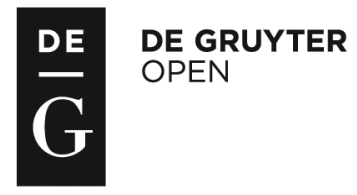

Administration, vol. 65, no. 3 (2017), pp. 1-13

doi: 10.1515/admin-2017-0021

\title{
How policy and budget proofing can advance human rights and equality in Ireland
}

\author{
Mary P. Murphy \\ Department of Sociology, Maynooth University
}

This special issue on policy and budget proofing comes in the context of renewed national and international focus on policy and budget proofing as mechanisms to advance equality and human rights. Focused on policy learning, this special issue aims to provide an overview of recent domestic and international developments to both inform and encourage Irish politicians, civil servants and civil society, equality and human rights advocates, as well as academics, to proactively engage with how policy and budget proofing can be advanced in an Irish context. Recognising the difficulties associated with policy transfer and the need for institutional fit with Irish budgetary and policy processes, the focus of the articles is relatively close to home, with lessons drawn from European, Scottish and Northern Irish case studies, and from Ireland, national and local. The papers include lessons from three different proofing families: human rights; gender and equality; poverty proofing or policy impact assessment. These three traditions reflect different foci and proofing approaches: some human rights processes focus on principles, mainstreaming approaches focus on the process of implementing budgets, while poverty proofing and impact assessment often focus on assessing distributional outcomes across a number of grounds. 
This special issue is timely. Ireland was regarded as a European and global leader when it introduced poverty proofing in 1997. The 2008 recession and subsequent years of austerity budgets brought renewed focus on demands for comprehensive equality proofing of Irish budgets. Alongside other actors, a 2013 Equality Budgeting Campaign brought considerable momentum to the demand. The newly established Irish Human Rights and Equality Commission's (IHREC) Strategy Statement 2016-2018 stresses building support for and advancing socio-economic rights and actions to deliver human rights and equality proofing of key legislation and budgetary processes, as one of its five key goals (IHREC, 2016).

In June 2015 the UN Committee on Economic, Social and Cultural Rights encouraged the Irish Government to better utilise rights-based budgetary governance processes to ensure that progress is made in the effective protection of economic, social and cultural rights in the postcrisis economy recovery. The committee recommended reviewing the Irish tax regime, with a view to increasing revenues to restore the precrisis levels of public services and social benefits, as well as the use of human rights impact assessments in the policymaking process. The May 2016 programme for government advanced this goal of human rights and equality proofing, committing government to 'develop the process of budget and policy proofing as a means of advancing equality, reducing poverty and strengthening economic and social rights' (Department of the Taoiseach, 2016). The subsequent focus has been on the development of institutions to support proofing processes in key government departments, including the role of social impact assessment in the Department of Public Expenditure and Reform.

Elsewhere, following the OECD's 2015 Review of Budget Oversight by Parliament: Ireland report, the focus has been on the budgetscrutiny role of the Oireachtas. Reforms to improve the quality of policymaking, resource allocation and accountability have included greater ex ante engagement of the Oireachtas in fiscal planning, supported by the provision of significantly enhanced information by government. The emerging budget scrutiny framework includes a Budget Oversight Committee and enhanced budget scrutiny by existing Oireachtas sectoral committees (including engagement with civil society). By mid 2017, steps had been taken to establish an independent Parliamentary Budget Office, which will provide analysis of taxation, expenditure and performance, as well as policy costings, and will equip parliamentarians to engage more effectively on budgetary matters. 
Over 2016/17 significant progress has been made in reshaping the Irish budgetary process, including the publication of a mid-June Spring/Summer Economic Statement, parliamentary engagement in the late-June National Economic Dialogue event, and earlier publication of draft Tax Strategy Group papers. Budget Day 2017 documents included improved distributional analysis and social impact assessments, and enhanced SWITCH analysis - the Economic and Social Research Institute's (ESRI) tax-benefit analysis - was available before the Social Welfare and Finance Bills. A new ex ante consultation process on the Stability Programme Update will also enable greater capacity for parliamentary comment, as will greater parliamentary engagement with mid-year expenditure reports. All this represents substantial progress in government commitment to enhanced engagement throughout, and especially early, in the budget cycle. This reform is an opportunity to integrate the principles of equality and human rights into the budgetary processes. As Quinn observes, in this issue, such budgetary and/or governance reforms have provided the stimulus and the framework for the introduction of gender budgeting in a number of countries. Indeed, she observes how fully implemented gender budgeting regimes are increasingly seen as 'an advanced form of PFM [public financial management] reform' (OECD, 2016). The proofing focus on realising outcomes is in line with 'modern' budgeting. It is now accepted that proofing is part of better governance and the process of evidence-informed management of national budgets.

However, much remains to be done. Constitutional constraints mean the budget prerogative is clearly with the Irish Executive, and in practice the focus of parliamentary engagement has been on the postbudget legislative stages between the budget and the Finance and Social Welfare Bills, while consultation with civil society has remained relatively symbolic. This special issue aims to contribute to advancing proofing in Ireland by exploring what can institutionalise effective proofing processes.

Proofing is most effective when there are clear national and departmental equality and human rights priorities, and when it is understood where and how advancing equality and human rights fits into, and contributes to, other national economic and social priorities, including economic growth. Effective proofing also enables the capacity to understand, from as strong an evidence base as possible, when policy can ameliorate or retrogress progress on equality and human rights. While Irish policymakers have some familiarity with 
poverty proofing, policy impact assessment, and gender or equality mainstreaming, there is less awareness of human rights proofing mechanisms. Ireland already engages with a type of human rights 'proofing' through periodic UN reporting mechanisms, but more can be done to utilise UN guidance on how to use human rights instruments, such as the International Covenant on Economic, Social and Cultural Rights (ICESCR), as a framework for government policy development. Figure 1 outlines core human rights principles against which budgets and policies can be assessed to evaluate whether they advance human rights principles, including progressive realisation, non-retrogression, minimum core obligations, maximum available resources, immediate obligations (substantive and process), and the central obligations to respect, protect and fulfil rights. These are developed in the pieces by O'Connell and Murphy in this special issue.

\section{Figure 1: Core human rights principles}

\section{Respect, protect, fulfil}

Respect: States should refrain from interfering with enjoyment of rights

Protect: States should prevent rights violations by third parties Fulfil: States should take appropriate measures to ensure realisation of rights

\section{Equality and non-discrimination}

Non-discrimination and equality are essential to enjoying economic, social and cultural rights

States obliged to guarantee rights without discrimination of any kind: race, colour, sex, language, religion, political/other opinion, national/social origin, property, birth/other status

\section{Progressive realisation}

Full rights realisation may be difficult in short-term, including due to constrained resources

States have a continuing obligation to take appropriate (legislative, administrative, financial, educational, social) measures - deliberate, concrete and targeted - to realise rights as quickly and effectively as possible

\section{Maximum available resources}

States must take steps to realise rights to the maximum of available resources

When resources are severely constrained, vulnerable people can be protected by relatively low-cost, targeted programmes 
Figure 1: Core human rights principles (contd.)

\section{Non-retrogression}

Retrogression occurs when states take steps that deprive people of rights they previously enjoyed; essentially the opposite of progressive realisation

States should not cut funding for essential goods and services where this would cause undue hardship, unless they can prove that they do not have the necessary resources

\section{Minimum core obligations}

At a minimum, states are obliged to provide for the 'minimum essential' levels of rights

A failure to provide this minimum is a failure by the state party to discharge its obligations

\section{Immediate obligations: result}

States have immediate obligations to realise substantive and crosscutting rights such as equality and non-discrimination

Such overarching rights are not subject to progressive realisation

\section{Immediate obligations: conduct}

To be consistent with a rights-based approach, mechanisms to deliver transparency, accountability and participation in the budgetary process must be provided

Citizens should have access to remedies in cases of rights violations

\section{Extraterritoriality}

A state's human rights obligations apply within and beyond its territory

To realise universal human rights, states should take action separately and jointly though international cooperation

This special issue includes three research articles, with the first, by O'Hagan, reflecting on the long journey to institutionalising gender and equality budgeting in Scotland; the second, by McInerney, focusing on policy impact assessment and the challenges of operationalising poverty impact assessment (PIA) in a local context; and the third, by Murphy, examining the potential application of human rights and equality principles to Irish taxation policy.

Also included are four forum articles, which provide an overview of key policy developments in human rights budget scrutiny (O'Connell), gender budgeting (Quinn), poverty proofing (Johnston) and the potential of the 2014 Irish public sector duty (Crowley). 
O'Hagan's research paper focuses on the experience of implementing gender and equality budgeting in devolved government in Scotland. Charting historical and conceptual developments from feminist economics and feminist institutionalist perspectives, the article highlights the significance of engaged political, civil society and policy actors; the need for clear conceptual framing; and the long time it has taken for limited progress to embed. The positive advances in integrating gender equality into economic analysis and the key budgetary principles of effectiveness and efficiency have been a key lesson. She offers insight into the institutional arrangements and advocacy that have maintained pressure for the Scottish budget process to be subject to effective scrutiny and to function as a key driver of gender equality.

McInerney's article keeps it local and examines the role of social/poverty impact assessment in contributing to the shaping of policy at a local level in Ireland. He first sketches the broader impact assessment landscape internationally, presenting key definitions and identifying underlying principles associated with three phases of preassessment, assessment and post-assessment, and exploring both technical and more 'theological' assessment complexities. The article highlights the key elements of Irish social impact assessment and examines the local-level experience in Ireland, in which he notes the highly innovative nature of poverty proofing as originally introduced in 1998. The low level of engagement with PIA processes at local level suggests that social PIAs have become largely subservient to other forms of impact assessment, particularly strategic environmental assessment. The article concludes that the local level does offer an important space for the practice of PIA but is unlikely to do so without the provision of appropriate capacity and resources, or without it being hardwired as a legislative obligation, albeit accompanied by mechanisms to sensitise and incentivise policymakers towards its usage.

Murphy follows this, focusing more closely on two human rights principles - maximum available resources and extraterritoriality - to examine various rationales for applying equality and human rights proofing mechanisms to fiscal policy. To date, Irish budgetary processes and major policy statements have not engaged with such principles. However, proofing fiscal policy is also relevant from the perspective of fiscal welfare, where taxation instruments, traditionally used as a revenue-gathering mechanism, are increasingly used as distributional mechanisms to achieve policy outcomes in pensions, 
health, housing and employment, with important equality and distributive dimensions, particularly from gender, age and socioeconomic perspectives. She offers a number of practical mechanisms and evaluative questions to guide equality and human rights proofing to fiscal policy, and points to the need to promote a public discourse which sees taxation as potential investment in society rather than a burden or cost on the economy.

Rory O'Connell's paper describes the experiences of using the perspective of human rights principles derived from the ICESCR to assess the Northern Irish budget. He does this by reviewing whether and how human rights principles overlap with the practice of a parliamentary committee involved in fiscal oversight of the 2011-15 Northern Irish budget. The aim is to observe congruence between the concepts used in such debates and scrutiny and the concepts used in human rights law. Crucially, as O'Connell argues, this is not an academic exercise. Such human rights principles will only be useful if they add value to the debates. Having provided background information on the Northern Irish political system and the timeline concerning the finalisation of the budget, he examines the budgetary discussions using the ICESCR obligations as a lens, and discusses evidence for congruence and the added value of a human rights perspective.

Ireland has also, under EU institutional requirements, considerable experience in gender impact assessment. A Gender Equality Unit in the Department of Justice and Equality introduced gender impact assessment guidelines for the National Development Plan 2000-2006, and an Equality Proofing Working Group of the Department of Justice, Equality and Law Reform was driven by the Equality Authority over the period $2000-8$. While at an overall level it is difficult to isolate outcomes generated through these processes, it is clear that a number of process innovations emerged, as well as greater transparency, accountability and culture change. Ireland has had less experience of gender budgeting. Sheila Quinn's overview of gender budgeting in European countries shows sustained support by national and regional governments, and a broad and diverse tapestry of experimentation, adaptation and integration. She argues that the International Monetary Fund's (IMF) recent commitment to a gender equality focus in fiscal policy, and its acknowledgement of the importance of gender budgeting to that goal, serves to give renewed impetus to the practice. Ireland has the opportunity to make up for lost time by borrowing from methodologies that have worked for its European peers. This paper sets out some of the best examples, 
illustrated through a number of brief case studies. She also makes a strong case for applying gender budgeting to revenue. Her observations on best practice draw out capacity issues, data deficits, consultative mechanisms, and the usefulness of embedding proofing in legislation and in the mainstream budget institutional processes.

While equality budgeting focuses on protecting groups on equality grounds, there is also a need to focus on what is often referred to as the tenth ground - socio-economic status. This is important in its own right as a focus of equality and human rights but also as a point of intersection for other equality grounds. Ireland was a global leader in the development of poverty proofing in the 1990s. Johnston focuses on the Irish experience of poverty proofing, asking, nearly twenty years on from its initial introduction, to what extent, if any, poverty proofing raised awareness of the need to design and implement policies to tackle poverty. Her article reviews how poverty proofing was implemented, whether this could have been done better, what worked in poverty proofing and also its limitations. Did it lead to the development and implementation of policies which resulted in poverty reduction? All of this she relates to the current commitment in the programme for government to budget and policy proofing as a means of reducing poverty.

International law obligations reinforce domestic law obligations, including the new Irish positive or public duty in Section 42 of the Irish Human Rights and Equality Commission Act, 2014, which requires public bodies to have regard to equality and human rights in the performance of their functions. Crowley locates equality and human rights proofing within this equality and human rights legislation, which established the IHREC. This act also legislated a statutory duty on public sector bodies to have regard to the need to eliminate discrimination, promote equality and protect human rights in carrying out their functions. The public sector equality and human rights duty is understood as new generation legislation for demanding a shift from reactive approaches to equality and human legislation to a proactive approach, where public sector organisations are required to establish and pursue equality and human rights goals. As Crowley observes, this new mindset of ambition requires proactive planning and new systems to embed equality and human rights in the procedures of public bodies. As such, it provides further coherence and depth to a sophisticated equality and human rights infrastructure with an intertwined mix of legislation, institutions, public policy processes and public policy plans. 


\section{Lesson drawing}

All the proofing examples reviewed in this special issue point out challenges in seeking to develop and improve proofing methodologies, and all concur that, while specific outcomes are hard to quantify, proofing does 'sensitise' policymakers across government to better policymaking. While each of the articles offers rich learning, a number of overarching lessons can be discerned. A key challenge is whether, or how, processes of budget and policy proofing as a means of advancing equality, reducing poverty, and strengthening economic and social rights might be integrated. This challenge is addressed by both Johnston and Crowley. Advancing socio-economic status as a target for proofing offers one mechanism to mesh equality with social and economic rights.

For O'Hagan, a key lesson is to integrate equality and human rights proofing into economic policy, government spending and revenue proposals. The theme of committing to the fundamental concept of marrying equality policy with economic policy also comes strongly from Quinn's paper and her analysis of the experience of Scotland, Sweden, Finland and Iceland. While one needs to be cautious about being overly instrumentalist in intent, the coupling of 'equality and efficiency dimensions' can be a strategic fit with other human rights governance principles. Spending plans, economic strategies and medium-term economic frameworks are vehicles for advancing equality, and equality or human rights goals become more embedded when they strategically fit with other government priorities and narratives.

Likewise, O'Connell reminds us that human rights are no panacea for economic woes but can shape and inform public discussion if and when translated into public policy mechanisms. The priority of protecting and realising rights should be discussed in the context of public debates on other public goods, including successful economic development. He explores the challenge of enabling all departments to understand how their work involves realising human rights, and in particular how use of human rights principles can keep the focus on realising rights through good budget governance, including a robust evidence base and a mechanism to guarantee participation, transparency and non-discrimination. As Crowley observes, progress in implementing the public sector equality and human rights duty means making visible the equality and rights objectives of department strategy statements. These strategic plans are key to implementing 
proofing at both national and local level, and to advancing how equality and human rights are central to the operations and ethos of public bodies. Consistent with this, O'Connell argues that a more explicit focus on realising rights can be achieved in the first stage through existing measures (strategies, explanatory memoranda), so progress can be measured against stated objectives.

Participation and consultation are key themes across articles. Both O'Connell and O'Hagan pick up the role of parliamentary committees. Given Irish parlimentary committees have been traditionally weak, proofing has potential to strengthen participation of the parliament in the budget process. Two international developments, the European semester process and the OECD review of the Irish budget process, have changed the landscape, and the Irish Parlimentary Budget Office will play an important role in enabling greater parlimentary participation in the budget process. Nearly all the authors raise the issue of consultation, which is seen as necessary and should be ex ante and based on draft budgets. Clearly this ex ante consulative requirement goes beyond the National Economic Dialogue initiative or the traditional approach to consultation informing the Department of Social Protection pre-budget forums. Social partners and other actors are crucial as advocates; see, for example, the engagement of the Scottish Women's Budget Group and their essential engagement with finance officials and ministers. Civil society partners (including academics) are critical as both direct participants and critical watchdogs of the proofing process. O'Hagan is mindful of the political dynamics and dimensions of a small country that is closely networked at the elite and advocacy levels, and where professional and political relationships exist, and activists often have multiple roles and identities.

While proofing is intended to expose the impact of proposed decisions on disadvantaged and vulnerable groups, a key issue raised by both Johnston and O'Connell is precisely who should be the subject of proofing. There are clear differences between persons protected under equality legislation and people considered vulnerable - for example, children leaving care, people in institutional care - and the need to incorporate the tenth ground of socio-economic status seems incontrovertible. A related question might be how do life-cycle grounds relate to the equality framework? Human rights also enable prioritisation. Realisation of minimum core rights should be prioritised at all costs while realisation of rights beyond the minimum core should be prioritised over those policies or projects that only 
indirectly realise rights, or do not realise them at all. To do this, data are crucial. As McInerney observes, data deficits are not an excuse for doing nothing. Human rights governance principles oblige governments to produce evidence to demonstrate progress in meeting human rights obligations. A rights-based analysis calls for consideration of the progressivity of the revenue-raising measures, as well as an assessment of the progress towards realising rights. Quinn focuses on the role of national statistical agencies collecting and managing sex-disaggregated and gender-relevant data. The data challenges in applying proofing in an integrated budget-proofing exercise are significant, but so too are the learning opportunities. A data audit is necessary, along with a national data committee and the incorporation of data-proofing requirements into the national data framework.

It is notable that in many countries the commitment to develop and embed proofing mechanisms outlasted a term of government and, in some instances, was spread over decades. Realistic time frames are important in expectation management but also raise the challenge of maintaining commitment. Commitments work best as obligations embedded in law, as some national and regional governments have done for gender budgeting (viz. Austria, Belgium, Andalucía). Quinn observes that, rather than providing standalone legislation, it seems best to legislate proofing into the framework of budgetary processes. Both Johnston and McInerney advocate such leglisative commitment to proofing in Ireland.

Johnston also underscores the importance of guidelines or 'worked examples' to demonstrate how proofing could be carried out and, like Quinn, stresses the importance of pilot schemes with relatively narrow application in the first instance (only civil service departments, only new policy proposals) and with systems for review and revision, if necessary. Specific government departments and local authorities, with support from the IHREC, can participate in proofing demonstration models by piloting different approaches. McInerney points to other implementation dimensions - for example, competing policy priorities or impact assessments and the low level of priority afforded to social assessments, the limited policy capacity at local level, and how those required to implement proofing perceive policymakers' level of commitment to the process. He offers proof that, with political will, local proofing is realistic and valuable.

What does all this mean for budget proofing and how can budget proofing mechanisms be incorporated into this emerging institutional 
framework? Lessons from elsewhere suggest that institutional reform to develop proofing capacity does not happen overnight but takes years to evolve, and needs to happen at a pace that enables the mechanism to be implemented in a realistic fashion. This means 'walking before running' and focusing on incremental building towards institutional capacity. In the medium term this means working to establish a well-resourced and fully functioning independent Parliamentary Budget Office with capacity to hold government and departments to account on proofing obligations. As data deficits are addressed, SWITCH as a tool can be developed across more grounds and include a wider number of public services; it also has the potential to inform ex ante proofing. Social impact assessments are important in providing a baseline from which to evaluate progress or retrogression. Prudent advice from economist Diane Elson recommends using medium-term economic frameworks, such as government spending plans and economic strategies, as a vehicle for advancing gender equality, or by extension wider equality and human rights objectives. Within the budget process, key stages such as performance budgeting and spending reviews are specific opportunities for proofing.

Quinn and Murphy make a strong case from both gender budgeting and human rights principles to incorporate revenue policy, particularly taxation, into proofing processes. Also, O'Connell advises that revenue-raising options, when pursued, should themselves be designed to be human rights compliant and, in particular, avoid hurting the most vulnerable. The Centre for Economic and Social Rights has developed OPERA - a four-dimensional framework for monitoring economic, social and cultural rights, which also offers guidance and tools for proofing, including a focus on measurable outcomes, on the degree of policy efforts, and on resource generation and state compliance. Given Ireland's poor record in revenue generation and low level of public spending as a percentage of GDP, the focus on evaluating effort to maximise resources appears particularly useful.

O'Hagan stresses the importance of the decision-making 'venue' and engagement with the core executive as essential to advancing gender equality policy, as well as the need for critical actors to make use of political opportunities. The role of civil society actors has proven crucial in many international examples. International engagement is crucial: all actors, including public servants, and state and civil society advocates, can make greater use of enabling UN guidance and principles. Murphy draws attention to specific recommendations of the UN Committee on Economic, Social and 
Cultural Rights to review Irish tax policy from the perspective of maximum available resources. Christine Lagarde used the IMF Conference on Fiscal Policy and Gender Equality in Washington, DC, in November 2016 to advance gender budgeting within the IMF's Fiscal Affairs Department, and to include it within the context of the IMF's Article IV country consultations. The EU has proven crucial to previous proofing initiatives, while discussion of gender budgeting across Europe is mindful of the influence of EU policy and directives.

Domestic agency appears crucial. Johnston observes how the Combat Poverty Agency championed proofing for ten years, publishing its own assessments of the annual budget. Political leadership is vital, along with both accountability and transparency. While proofing is a year-long exercise, the high profile of budget day in the Irish political calendar is an opportunity for accountability on realising equality and human rights. The Minister for Finance and for Public Expenditure and Reform can demonstrate commitment by including a comprehensive human rights and equality statement in the budget statement. Leadership is also important in ensuring all departments, as part of their Section 42 public duty, outline key human rights and equality statements, and link budget expenditure to advancing and realising such goals. Learning from Scotland, leadership, momentum, staying power and synergies can also be generated by establishing a national proofing committee to lead and advance the institutional framework for proofing. The ESRI, the National Economic and Social Council, and the IHREC all have clear support and oversight roles that need a coordinating governance process, which could also incorporate the chair of the Budget Oversight Committee, experts such as the Irish Fiscal Advisory Council and the Central Statistics Office, independent experts and civil society.

\section{References}

Department of the Taoiseach. (2016). A programme for a partnership government. Dublin: Department of the Taoiseach.

IHREC. (2016). Strategy statement 2016-2018. Dublin: IHREC.

OECD. (2016). Gender budgeting in OECD countries. Paris: OECD. 